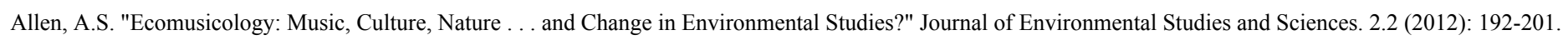

DOI 10.1007/s13412-012-0072-1.

Made available courtesy of Springer Verlag. The original publication is available at www.springerlink.com. Reprinted with permission. No further

Review Essay reproduction is authorized without written permission from Springer Verlag. This version of the document is not the version of record. Figures and/ or pictures may be missing from this format of the document.

Ecomusicology: Music, Culture, Nature ... and Change in Environmental Studies?

A. S. Allen

University of North Carolina at Greensboro

PO Box 26170, Greensboro, NC 27402-6170, USA

email: aaron.s.allen@gmail.com

John Luther Adams. The Place Where You Go to Listen: In Search of an Ecology of Music. Middletown,

CT: Wesleyan University Press, 2009

Helmi Järviluoma, Kytö Meri, Barry Truax, Heikki Uimonen, and Noora Vikman, eds. Acoustic

Environments in Change \& Five Village Soundscapes. Joensuu, Finland: Tampereen ammattikorkeakoulu, 2009

David Ingram. The Jukebox in the Garden: Ecocriticism and American Popular Music Since 1960. Amsterdam, New York: Rodopi, 2010

Giuseppe Gerbino. Music and the Myth of Arcadia in Renaissance Italy. Cambridge, UK: Cambridge University Press, 2009

**

Sensing Change

The five senses: touch, taste, smell, sight, hearing. We rely on them daily, professionally, and personally — each can inform our understanding of the world and evoke memories of places and times, both distant and dear. Public policy and science, however, are guided primarily by the visual: maps, not the smell of rich soil or the feel of damp air, are used to understand local and national borders; photographs, not the feel of 
sticky blood or the cold metal of a weapon, provide evidence for use in court; and data such as lists of ingredients, not individual natural and artificial components to be tasted, are provided in text to be read. Scholarly research, after all, is presented in visual form in the text of a journal: maybe in braille but not as light shows, perfumes, or food, and, while those words in a journal may be read aloud, they are certainly not meant to be performed or sung.

This ocularcentrism is not new. Heraclitus (c. 500 B.C.) wrote in his Fragment 101a that "the eyes are more exact witnesses than the ears," and such empiricism has long provided a basis for intellectual endeavors (Levin 2002, 1). As philosopher David Levin has explained, "philosophical thinking in the Western world was drawn to the tuition, the authority, of sight. . . For those of us who can see, vision is, of all the modes of perception, the one which is primary and predominant, at least in the conduct of our everyday lives” (Levin 2002, 2). Historian Mark Smith also recognizes the hegemony of the visual, and he traces modern thinking about the subject to Marshall McLuhan's "great divide" theory, which emphasizes the visual at the expense of the aural:

[McLuhan] maintains that following the invention of movable type in the sixteenth century and under the ensuing influence of an eye-centered Renaissance and Enlightenment, vision came to dominate Western thinking, serving as authenticator of truth, courier of reason, and custodian of the intellect, while the senses of taste, touch, and smell, especially, were essentially sidelined... [T] he print revolution was also responsible for braiding sight and logic, seeing and reason, vision and objectivity. ... [S]ight — so empowered by print — objectified what was seen, giving the viewer perspective, distance, balance, coolness, detachment, and a growing sense of self.

The situation with sound differed in that it "penetrated and surrounded listeners (often quite emotionally)" (Smith 2007, 9-10). Smith is, however, critical of McLuhan's binaries and oversimplifications, and both he and Levin encourage us to move beyond privileging the visual toward a multisensory understanding of the world.

Environmental studies and sciences (ESS) engage with understanding the world around us, chronicling 
ecological changes and impacts, and exhorting action to halt and remediate the problems that humans created. Most college and university environmental programs include a wide array of classes in the natural, physical, and social sciences — the key arenas where environmental problems unfold, play out, and are addressed (Clark et al. 2011a and 2011b). Less central to such curricula, however, are humanistic approaches, although the fields of environmental history, ecocriticism (i.e. environmental literature), and ecological art are represented in some programs (Parini 1995). These approaches, too, privilege the eyes.

Environmental crises require all the intellectual, political, scientific, and cultural resources we have to confront them. As David Orr has written, "despite the great range and diversity of disciplines and perspectives necessary to an informed ecological worldview, the subject comes down to the one big question of how we fairly, durably, and quickly remake the human presence on Earth to fit the limits of the biosphere while preserving hard-won gains in the arts, sciences, law, the open society, and governance, which is to say civilization" (Orr 2010, xvi). Given the severity of the environmental crisis and the need to understand and address it in as many ways as possible, it is surprising that sound and music have still not become more common methods to study, organize, educate, and effect change regarding the environment.

Aural approaches are not entirely absent from environmental and ecological studies, of course. The winter 2009-2010 volume (26/3) of the National Parks Service’s journal Park Science provided a special issue that considered soundscapes and the impact of noise. More recently, the entire November 2011 issue of the journal Landscape Ecology (26/9) elaborated on the "new" discipline of "soundscape ecology," and a new volume of essays provides theory and application for the field of "sound studies" (Pinch and Bijsterveld 2011). Since the mid-twentieth century, avian bioacoustics has been a major field of research (Marler and Slabbekoorn 2004). Even before that, evolutionary studies since Darwin have considered birds, if in contested ways (Mundy 2009); the avian world informed medieval European conceptions of music, music theory, and musicians (Leach 2007). Historical study, too, has taken up interest in hearing the past (Smith 2004). Environmental education has taken initial steps to considering the ways music can contribute to learning about the natural world (Turner and Freedman 2004). As an interdisciplinary approach that 
combines science with art and the humanities, ecomusicology can contribute to these endeavors. Moreover, ecomusicology has the potential to do what environmental studies programs do best: bridge disciplines in creative ways to improve students' analytical reasoning and environmental problem-solving skills.

Ecomusicology encourages the consideration of sound and music as part of nature — as something that can both inform cultural understanding of the environment and help us reflect on humanity's place in nature. Doing so can contribute to improving environmental education in particular and to addressing the environmental crisis in general. Four recent ecomusicological books illustrate the diverse ways of engaging with sound, music, human culture, and the natural world. Ecomusicology is an emerging field of study that draws on a wide range of disciplines; it is not a new discipline but rather an umbrella or patchwork of related fields with complex intellectual/ecological interactions, often implicit to or unacknowledged by the authors themselves. These books demonstrate that this realm of humanistic and artistic research and engagement can be beneficial personally, intellectually, and practically to scholars in ESS. Ecomusicology is no panacea, and it can suffer from many of the same problems found in ESS curricula that Clark et al. (2011a and 2011b) outlined. Notwithstanding such reservations, ecomusicology can help diversify the curricula and broaden the impact of ESS programs.

The term "ecomusicology" elicits quizzical reactions from even those who ostensibly practice it. Elsewhere I have defined ecomusicology as "the study of music, culture, and nature in all the complexities of those terms. Ecomusicology considers musical and sonic issues, both textual and performative, related to ecology and the natural environment" (Allen forthcoming 2013). Although the aims of this field are not new — something akin to it has been investigated since Ancient Greece in the West and is fundamental in nonWestern societies — what may be new is the organized approach of a community of scholars and musicians (see Allen et al. 2011, and the website www.ams-esg.org). A term as broad as ecomusicology is, on the one hand, useful in its inclusiveness — much as the term "environmental studies" has proved useful in drawing together distinct but related fields and disciplines. On the other hand, the lack of specific disciplinary methodologies could make ecomusicology a vague construct — particularly because individual practitioners, 
whether they self-reflexively acknowledge they are "doing ecomusicology" or not, may approach their research, teaching, and communicative efforts in different ways. From a scientific perspective that values the achievement of truth, even in small incremental steps, it may feel maddening to approach scholarship in so many different ways, but I find that such diverse approaches can be both intellectually stimulating and ecologically beneficial.

\section{Listening for Change}

John Luther Adams's book The Place Where You Go to Listen is, as one might expect, fundamentally about listening. It recounts Adams's transformative experiences of listening to the world around him, and how he wants others to have such experiences. Adams is continually developing and striving for an "Ecology of Music," and this book elaborates on his ideas and projects in that regard. Given the social and environmental problems that plague the planet, Adams believes that striving for such an "Ecology of Music" is necessary not to "change the world" but rather to change "the quality of our attention to the world" (103, emphasis in original).

Adams is a composer most known for his works evocative of the northern landscape. In the 1970s he campaigned for Alaskan wildlands and served as the executive director of the Northern Alaska Environmental Center. The book chronicles and explains his sound and light installation, also called The Place Where You Go to Listen, located in the Museum of the North at the University of Alaska in Fairbanks. Renowned music critic Alex Ross describes, in the foreword based on a New Yorker article (Ross 2008), his experience hearing the aurora borealis, as presented in The Place, "in an infinite musical work that is controlled by natural events occurring in real time" (Adams 2009, ix). The Place is entirely electronically generated from noise rather than recordings of the environment, so it is not a soundscape. Adams took the title from "Naalagiagvik," an Iñupiak place name on Alaska’s Arctic coast that means “The Place Where You Go to Listen"; the legend recounts a woman who sat quietly there and, listening attentively, could understand the birds' languages and hear unseen voices (110). 
There are two tripartite sections: one explains synthetically Adams's philosophies, aesthetics, and compositional and data techniques; the other chronicles the experience of creating the work. The latter provides the primary sources for the former, which preface ("In search of an ecology of music") and follow ("Hearing where we are," and "An ecosystem of sound and light") the three chronicles. (That layout does provide for some redundancies, but they could be instructive if traced to show the development of Adams's ideas, his struggling with them, and their ultimate deployment.) The bulk of the book is an extended series of journal entries stretching from the winter solstice of 2003 through the start of spring 2006, just after the vernal equinox opening of The Place. The three chronicles recount the preparations ("Always getting ready"), the development and refinement of the sounds ("Studio notes"), and the construction, setup, and initial experiences of the installation ("In the place"). Together, the six parts are a sensitive artist's subjective reflections synthesized with the objective descriptions of a careful scientist. In fact, although he sometimes presents them as binary opposites (a problematic position considering the intellectual history following from Snow 1959), Adams bridges these two worldviews while simultaneously respecting their differences. In essence, they form a transdisciplinary dialogue with each other — a model Adams tries to exemplify in his life and work.

In the chronicles, Adams reflects on the meanings of truth, the changing seasons, studio work, camping and concert trips, indigenous wisdom, the wildfires that ravaged Alaska in 2004, technology mediating sound, the U.S. elections, personal spirituality, the physics of sound, single-malt whiskies, hanging drywall, "big oil" in Alaska, and the laborious stages of musical composition (among many other topics). All the while he melds observation and feeling: Adams combines geological data and computerized algorithms with translations into sounds that he seeks out and analyzes with his ear and intuition. But the chronicle is not just about Adams's music, although we learn much about that, or just about how nature reinvigorates and inspires his work, as it does. As an astute observer of the Alaskan landscape for nearly three decades, he also offers a clear and compelling voice about the world around him, particularly about a changing northern climate in the context of global warming. New bird species, changing calendars, abnormal weather events: 
these all play into his transformative hopes for what his art, and especially The Place, might elicit in listeners.

Also in the chronicles, we learn of sounds created by the aurora borealis, widely reported but inexplicable by science (although perhaps a form of synaesthesia) (39-40), as well as Adams's experiences watching the aurora and trying to convert magnetometer data into sound that dances like the northern lights. Adams relishes this challenge: when a significant geomagnetic storm occurred, he couldn't see the lights because of cloud cover. "Inside The Place [however] we would have been able to hear this storm" (35). Later, once The Place is built, Adams is unable to view a rare moon cycle event, again due to clouds, but he is able to hear it: "This is what The Place is all about: extending the reach of our senses, allowing us to hear the inaudible and the invisible" (75-76). Similarly, the some 12,000 annual earthquakes in Alaska are mostly too small to feel, but The Place registers them through the "Earth Drums" (132-137). In his experimentation with electronically processing noise (aperiodic sound) to isolate tones (periodic sound), Adams and his assistant realize they are listening differently: "[O]ur ears have become highly sensitive to hearing tone within the breath of the world around us. Leaving the studio this evening, we stop dead in our tracks. The wind is flowing over the ridge and down through the forest. It sounds to both of us like a choir of angels singing" (48). The same "kind of sonic chemistry, or alchemy" (49) that Adams thought he was carrying out on sounds was being carried out on himself.

Adams aesthetic philosophies are more than just reflections on the personal artistic realm; they amount to how creating The Place helped clarify and put into practice his dynamic and developing musical ecology. Most composers communicate in sounds; music conveys their messages. But Adams has a talent for the written word as well, making this an accessible book for any interested reader. He has authored two other books and many articles; in addition to the requisite discography, this volume also contains a useful bibliography of writings by and about Adams. Adams provides an eloquent understanding of the natural world seen through artistic and scientific lenses, and he models a kind of consilience that E.O. Wilson (1998) promoted.

The final synthetic section goes into technical details about the data and manipulations that affect sound 
and light in The Place. Here are further details about Adams's "sonification" of natural phenomena, which is what he calls the "process of mapping data with some other meaning into sound" (113, emphasis in original). The natural phenomena that concern Adams are seismic activity, geomagnetism, cloud cover and visibility, movements of the sun and moon. While some of the "how" questions come up in the chronicles and earlier two synthetic sections, separating the technical details is useful because it allows for a readable, mostly jargon-free text while still providing, eventually, answers for the technically curious reader. As Adams conceived The Place "as a contemplative space for tuning our ears" (110), and as he understood his processes as "tuning the world" (113), he fits into a long line of thinking about sonic environments. On the one hand, these date back to ancient Greek ideas of the sounding cosmos, or the harmony of the spheres; on the other hand, they connect Adams with Canadian composer, soundscape artist/scholar, and author R. Murray Schafer's foundational writings from the 1960s and '70s (Schafer 1994). Other contemporary composers have continued heeding Schafer's advice and, like Adams, meld art and science. For example, in addition to his work promoting serious listening (Ingram 2006), composer David Dunn has collaborated with scientists to listen to pine bark beetles, stopping their infestations using bioacoustics (Dunn and Crutchfield 2009).

In a sense, Adams concludes his book with an answer to that age-old philosophical question about the tree falling in the forest. Even when no listener is present, the sounds of The Place exist, as in the natural world. "But when a listener is present, her awareness transforms this sound environment into an ecosystem of music" (139). It is this transformative experience that Adams believes can change how we listen and change for the better how we pay attention to the earth.

The collection of essays Acoustic Environments in Change (AEC) by Järviluoma et al. also stresses the importance of listening. Instead of a single artistic conception of listening or a developing musical ecology, however, the interdisciplinary approaches in AEC stress historical and cultural changes and strive to determine the meanings of listening to a variety of small-scale social soundscapes. As Adams was pushing the commonly understood boundaries of the contested term "music," soundscape studies push even 
further: while some soundscape works are presented as art (music), others are presented scientifically, as data to be analyzed and understood. Rather than different categories, these are two potential poles on a continuum, with most soundscape work moving freely between them. Consider, for example, the work of Bernie Krause, a soundscape artist/scientist and prominent figure in the well established fields of biomusic and bioacoustics: he earned a Ph.D. in bioacoustics and continues scientific work, and he has produced over fifty albums (Krause 1998, Krause 2002).

In a turn of phrase similar to how Inuit might emphasize hearing over seeing (see Adams 2009: 101), lead editor Helmi Järviluoma writes that the basis of AEC was the desire to return to five small towns “studied by the World Soundscape Project in the mid-1970s ... and hear how the villages are doing" (11). (One curious change between the studies is that the later one added a sixth village, Nauvo in Finland; other than that it was interesting and many researchers lived near by, it is not clear why this addition was necessary.) No one would doubt that the villages have changed, but the questions are how, why, and what can be done in the future. Ten essays, plus an introduction and epilogue, revisit and elaborate on the foundational work of Schafer et al. (1977) in Five Village Soundscapes (FVS), which is reprinted in the volume with a new preface by another key soundscape composer/scholar, Barry Truax. The four included CDs illustrate soundscapes from both the FVS and AEC projects. As a whole, the volume provides a wealth of information but also engages with developing methodologies that still need refinement. The AEC authors are not trying simply to reproduce and compare results with the FVS; rather, they recognize that past procedures are not always going to work with present and future studies (18).

The original FVS work was in response to problems that Canadian cities, especially Vancouver, were experiencing with lo-fi sound conditions, as Schafer and his Canadian team found; FVS sought examples of hi-fi sound conditions to analyze and to learn from. Lo-fi conditions are "obscured in an overdense population of sounds" (e.g. noise from traffic), while hi-fi are those "in which discrete sounds can be heard clearly because of the low ambient noise level" (Schaffer 1994, 43). The FVS study chose five sites — Skruv, Sweden; Cembra, Italy; Bissingen (an der Teck), Germany; Lesconil, France; and Dollar, Scotland — that 
were "viable acoustic communit[ies ...] where sound played a significant and positive role in the soundscape and the lives of the inhabitants" (Schafer et al. 1977, as in Järviluoma et al., 287). Each had a significant industry of some sort (manufacturing, fishing, agriculture, an elite academy), and each had fewer than 3,000 inhabitants. Despite many acknowledged problems with method — and the especially problematic approach that presumes the traditional village soundscape "is analogous to that of a pre-literate culture or the natural environment itself” (394) — the FVS study's aims were “to enquire into the different types, quantities and rhythms of sounds heard [...] and to show the relationship of these sounds to the structure of each village and its life" (290).

The FVS researchers recognized that their primarily quantitative approach could not get at many issues; AEC broadened the approach to include more qualitative, reflective, and interpretive methods. To provide aural profiles of the villages, data included: historical information, interviews, sound preference tests, traffic calculations, sound recordings, and qualitative listening-walks. FVS researchers provided numerous maps of characteristic sonorities (hums, pitches, and even notated musical chords) at certain times of day at locations relating to industry (factories), nature (water, mountains, winds, vegetation), and society (churches and bells, foghorns, schools). Preference tests of inhabitants, mostly school children, determined characteristic, pleasant, and unpleasant sounds. Other considerations included architectural layout (street diameter, building construction, elevation), personalities (public socializing, public musical performances), and transportation (roads, transport methods, traffic frequencies). They also characterized the acoustic materials of water, stone, wood and other materials that humans used and that were part of the setting of each location, as well as distinctive, valued foreground sounds (e.g. bells, whistles of trains and factories, etc.) that have local importance. The villages were certainly not pristine: encroaching air traffic, highways, and industrial sound impinged on what the researchers and locals deemed characteristic sounds.

The researchers for FVS worked on the simple assumption that "sound reflects some aspect of village life" (389). These can be positive and characteristic, as in Lesconil where the regular solar winds were important both for fishing and for carrying sounds in daily patterns, or they can cause trouble, as in 
Bissingen where aircraft represented a "masking power in the [aural] environment" (389). The FVS researchers found that the most significant problems across the villages were increases in motorized traffic, which desensitized the residents bathed in a constant lo-fi soundscape. This simplification of the soundscape, from a hi-fi to a lo-fi one, is not what researchers expected in regard to the usual narratives of “progress" (technological, economic, etc.) — such "progress” typically implies increasing complexity. As a result of the simplified lo-fi conditions, residents developed a "lack of inclination to listen carefully," which resulted in "reduced social interaction and community cohesion," itself measured via sonic interactions (393).

FVS posited that acoustic design could "be used to counteract the negative effects of technological economic growth within a community" through the following: increasing the variety (range) of sounds in a soundscape, promoting a complexity (quality) of related and functioning sounds, and establishing controls that balance (allow for the coexistence and interaction of sounds in) the large-scale soundscape of a place (394). This agenda calls for acoustic designers to engage politically and socially both with the public sphere and with traditional music studies; these latter music scholars engage in a "form of acoustic education [that] is not concerned as yet with environmental problems" (395). The FVS authors argued ultimately for a field of acoustic design that took a "positive approach to the problems of environmental sound, as opposed to the primarily negative approach of most noise studies"; furthermore, acoustic designers should be engaged with "larger questions of acoustic ecology, the balanced relationship of individuals and communities with their sonic environment" (395, emphasis in original).

The AEC project, carried out in 2000, repeated some of the FVS tests and data collection methods but also allowed for the individualized approaches of the five Finnish scholars. AEC provides a wealth of new data and appropriate comparisons. Rather than standardized quantitative and qualitative methods, the overall approach is more philosophical, with considerations of issues such as silence, nostalgia, and power. FVS made some problematic assumptions and had methodological problems; similarly, AEC provided ample (perhaps too much) hand-wringing about methodology (34ff and 244ff). Both situations are 
understandable from a young discipline that could use wider and more self-reflexive praxis. FVS was carried out from the perspective of communication studies using quantitative methods; AEC comes from anthropology, cultural studies, and ethnomusicology, in which qualitative methods are more common. Comparisons about change, and non-change, are best made with the shared quantitative methods, and these are summarized and reported in the introductory and concluding chapters.

Already in the 1970s, FVS found that the villages were changing; the AEC study confirms and traces that but also seeks to answer bigger questions about meaning. The fountains of Cembra stand out as an example of sonic change that is related to the larger social and environmental issues of both studies. In the 1970s, Cembra's many fountains were used for daily washing and communal gathering. By 2000, they were dry because the collective outdoor laundries were replaced with private facilities. Residents found that the "steady drone $[. .$.$] was one nostalgic reminder of the times they worked together" (266-67). (This "drone"$ may seem like a lo-fi noise similar to traffic, but it differs because the fountain lacks the aperiodicity of traffic noise, because of its role as a community-valued "soundmark," and its "pacifying quality"; see Schafer 1994, 10, 18, and 228.) Sound preference tests both acknowledged the continued preference of nature sounds and recognized changes in the social fabric of the places, as with Skruv's factory hooters no longer marking the end of the work day and releasing a torrent of bicycling workers to return home. Traffic tests noted the (perhaps expected) general increase of traffic, as in Cembra, where a new mine opened in the 1980s, thus bringing in an influx of foreign workers and a new neighborhood to the village. But, as a contrary case, Skruv's loss of its industrial base and train station resulted in less traffic noise.

The ten core chapters provide engagement with larger meaning-making processes in the villages. Memory and nostalgia are the subject of the last five of these, three of which were authored by Helmi Järviluoma, who writes that the past "is always mediated and being produced through memory work, acts of remembering in which we present ourselves both to ourselves and to others” (29). Järviluoma first explores collective and individual memories of the past soundscape in relation to the present in Skruv. Further reflections on method regarding nostalgia are discussed in the context of changing sounds on farms in 
Bissingen; her study of a single farmer's self-reflective memories is instructive of the changes, positive and negative, that accompanied going from the scythe to the tractor. Through sonic memory walks around Lesconil, Järviluoma discusses the role of women's remembrances of sounds to create shared understandings of places, communities, and the past. Tero Hyvärinen's interesting contribution, "'Putt putt' and 'mur' — Old inboard engine and nostalgia," discusses the nostalgia in literature and interviews (and in himself) for the calming sounds of the now-rare kerosene motor used in the island community of Nauvo. Heikki Uimonen's piece about the village blacksmith in Dollar connects memories with what was neither an ugly nor beautiful but rather common sound, the silencing of which through retirement signaled broader economic changes. Of the five other chapters, four by Noora Vikman explore aspects of Cembra, from changing soundscapes to silence, and from sonic patterns in times of day and seasons to the spaces and sounds of men's choirs. Despite the seemingly mundane topic of silence, that chapter in particular is interesting for its engagement with aspects of perception, tourism, and nature. The remaining contribution, which is an appropriate first chapter after the introduction, is Heikki Uimonen's consideration of cognition of sounds regarding how and what we hear.

The authors emphasize the co-construction of soundscapes: "villagers are simultaneously producers and audience" (269). This leads the AEC authors to two concluding observations that provide hope and opportunities for the future. First, the commodification of silence has wide implications, regarding both tourism and law (e.g. noise directives such as those in the European Union that require member states to provide silent areas for their citizens). Second, the most pressing environmental issue, climate change, requires global solutions; but local actions can contribute to global responses, and soundscape studies can connect with studies of economic development, quality of life, and environmental sustainability to inform such actions.

The volume would have benefited from a native English-speaking copyeditor and some tightening of the whole, and the result is that it is not accessible to the layperson or beginning undergraduate (at least not without effort). But such quibbles do not diminish its importance. Perhaps the most relevant conclusion in 
AEC is that "people still do live with their ears open" (267). Here is a contrast with Adams: both FVS and AEC recognize the need for more acoustic design — that is more large-scale engagements at the community and society levels to promote healthy, beneficial, responsible soundscapes. While Adams would not disagree, he emphasizes the training of listeners, almost individually, through works of art. I find that both approaches — Adams's musical, personal, and artistic, and the AEC/FSV's sonic, ethnographic, and qualitative — are necessary. Further, these approaches need to link with science and public policy to effect larger change. As "soundscape ecology" has recently been theorized as a "new" field related to landscape ecology (Pijanowski et al. 2011), such possibilities seem within earshot.

\section{Changing Histories of Music}

From contemplating sounds to considering music. The shift might be considered paradigmatic of the nature-culture divide: the existence of sounds, even without listeners, contrasts with the reification of art by human listening and thinking. But, in reality, no neat black-white, here-there divide exists. One’s position on the question — is it music? — is a matter of taste, cultural conditioning, and biological fortune. Some hear music in the wind in the trees, others hear noise emanating from the concert hall (or, these days, earbuds). The following two books, however, connect music (the works themselves, the artists who create and make them happen, and their listeners) and history (of music, of society, of ideas) with diverse ways of knowing both. On the one hand, the agendas of these books are more straightforward than the previous two; on the other hand, they cover together an exceedingly broad range of musical styles, cultural contexts, and environmental issues.

As a book on music seen through the lens of ecocriticism, David Ingram's path-breaking The Jukebox in the Garden is the first of its kind and wonderfully accessible. It is a selective historical survey of popular music during the period of modern environmentalism, i.e. since the 1960 s, that "traces the various ways in which American popular musicians reacted to [...] lamented, and protested against [...] the degradation of the Earth.” Rather than concern himself with just musicians and songwriters, however, Ingram connects their 
works with contemporaneous ecophilosophical thought, "according to which music, amongst all the arts, has a special affinity with ecological ideas" (11).

The title references a seminal book of ecocriticism: The Machine in the Garden (Marx 1964). Leo Marx used the intrusion of technology, especially distant or intruding trains, in pastoral scenes of literature as a metaphor to convey the ideas of the simple pastoral and the complex pastoral: the former indicates a sentimental withdrawal to the idyllic countryside, the latter calls into question or brings some irony to — or even politicizes — the illusion of peaceful glades. Ingram leaves it to the curious reader to make this connection, as Marx's work informs explicitly only one chapter of the book. The Jukebox in the Garden, however, is a corrective to the assertion in Marx's notion in The Machine in the Garden that the simple and complex pastoral were indicated by low and high culture, respectively (see Ingram 2010, 11-12ff, 54ff). Ingram is out to demonstrate that popular music does indeed relate to and convey sophisticated ideas such as Marx's complex pastoral.

Although Ingram's book is intended for undergraduates and general readers, there is no primer on ecocriticism, which may be taken as a statement of where that field is now and how accessible its ideas are. Ecocriticism is a subfield of literary studies that considers cultural products that imagine and portray humanenvironment relationships (Garrard 2004). Ingram's work is mostly jargon-free and not at all technical, written as it is by a British professor of American studies who has been considering ecomusicological ideas for many years. Ingram summarizes, and critiques, complex philosophical issues in concise and direct language, and he makes clear his own suppositions and positions. His work complements that of other interdisciplinary scholars: musicologist Denise Von Glahn (2003) connected art music and iconic American places, musicologist Brooks Toliver (2004) drew on ecocriticism to relate popular concert-music composer Ferde Grofé's Grand Canyon Suite to ideas of preservation and conservation in the United States, and anthropologist Mark Pedelty $(2008,2011)$ has considered popular music from Woody Guthrie to Green Day in the context of environmental issues. Together with Ingram's book, these works can serve selectively in ESS curricula to illustrate key concepts and widen the disciplinary breadth of the field. 
Ingram's four chapters in Part One develop significant concepts of environmental thought in relation to popular music, particularly regarding aesthetics, high/low art, naturalism, the pastoral, deep ecology, and New Age thinking. Although prefaced with some theory — from art music composers (John Cage) and musicologists (Susan McClary) as well as ecocritics (Lawrence Buell) and philosophers (Theodor Adorno), among others — the bulk of the book does not theorize or speculate but rather correlates environmental ideas and issues in relation to musical figures and works. All the while, however, Ingram maintains a critical distance that is exemplified at the end of Chapter One, which outlines three important philosophical approaches (humanist Marxism, postmodernist musicology, and post-structuralism). These philosophies meet with music aesthetics and environmental ethics in order to collectively address the "utopian potential of music to prefigure a good society, including a more benign relationship between human beings and the natural world" (23). After pointing out strengths and weaknesses of those approaches, Ingram offers an alternative model for the book that acknowledges the "partiality and fallibility," as well as the usefulness, of each approach (35). He calls his model "critical realism," which claims "that human conceptions of 'nature' are multiple and varied, ... that nature is socially produced ... [but also] that nature exists external to human beings, and is objectively knowable" (33). This is a skeptical but practical understanding that rejects extreme relativism and total scientism and instead finds a balanced, flexible middle ground.

One example of Ingram's critical realism is his Chapter Four, "Eco-listening," which engages with the "recurrent claim [...] that listening to music has the potential to be an ecologically attuned activity" (59-60). After outlining the main tenets of immersive listening and New Age rhythmical entrainment, which seek to create an ecological rather than atomistic sense of self and to build a sense of social-ecological community, Ingram critiques these philosophical positions for their being presented and conflated as scientific theories:

Listening to music, then, is an activity determined by biological, cognitive and social factors in a more complex way than that suggested by New Age and deep ecological philosophies... Moreover, these ecophilosophical claims ultimately fall into the same trap as the theories of visuality from which they emerge: that of isolating one sense from the others, while ignoring the ways in which, in everyday 
human perception, all of the different senses interact (70).

In other words, listening — no matter how careful, critical, contextual, or ecological — is not the sole solution. Listening belongs in an ecology of senses. (Is this why John Luther Adams felt compelled to include light and colors in The Place?) Ingram's critical realism continues:

But even this enhanced sensory awareness, which can certainly be encouraged by an appreciation of music, and of the arts in general, will only be a small step towards positive environmental change, which will depend much more on questions of politics, economics and history too often omitted from [these] kind of ecophilosophical discussions (70).

Ingram is not damning the ecomusicological effort in its entirety. Rather, he is keenly critical of myopic conceptions of the field and, in particular, of certain approaches that lack rigor and critical self-appraisal.

Part Two includes eight chapters organized by genre to explore a variety of themes. Ingram covers many of the major popular music styles and, despite the clear chapter demarcations of them, recognizes their overlaps. Through broad histories and case studies of genres, artists, songs, and ideas, Ingram explores the variety of ways that American popular music has negotiated human-nature relationships: from the rural cowboy and wilderness conservation in country music, to pastoral irony and the hippie counterculture's contradictions in rock; from protest music in folk and hip hop, to race, class and naturalism in the blues; from nature as a place of spiritual enchantment in folk music, to neo-Romanticism and the role of technology in electronica; and from globalization and environmental discourse in world music, to ecological awareness through improvisation in jazz. Ingram's goal is part surveying to show breadth, and part intellectualizing to show how these genres and artists relate to environmental ideas.

Ingram recognizes the desire to evaluate art works ethically as well as aesthetically, but in the end he finds that "it is counter-productive to be overly prescriptive when it comes to art" and instead promotes aesthetic pluralism (17). No "one form of music is more 'natural' or 'ecological' than any other" (233); rather, they use different strategies, particularly sentiment and didacticism. John Denver and other simple pastorals are one way to encourage emotional connections with the natural world and express concern. 
Didacticism can sometimes be so complex as to undermine the usual simple messaging of rock, but occasional examples, such as Randy Newman's “Burn on Big River” (1972) about the chemical fire on the Cuyahoga River, can be “topical without trivializing the issues” (235). An excellent example of Ingram's balance of ethics and aesthetics comes through in this sentence about Michael Jackson's "Earth Song" (1995): “[]f Jackson’s lyrics reduce environmental apocalypse to a series of predictable questions ('What about the rain?', 'What have we done to the world?'), his vocal performance adds musical interest, as he embellishes this mounting series of rhetorical questions with whoops, sighs and groans, while the gospel call-and-response arrangement drives the song towards an impassioned, if melodramatic climax.” Ingram also critiques Jackson as the "pop star as lone saviour of the [Earth]" and record label Sony's commodification of protest (236). This fair, skeptical yet engaging and rational approach also allows Ingram to do all of the following: to represent others' complaints that music has no place in philosophy and then counter it with examples of how music can provide worthy insights into humanity; to present anti-rational Romanticized New Age neo-pagan ideas and critique them but defend the usefulness of considering them; and to recognize the ongoing and provisional scientific research into music while recognizing that it "does not reveal a world any less full of wonder than that conjured up by idealist eco-mysticism" (239).

In sum, Ingram's intellectually flexibility, wide reading, clear writing, and engaging examples present an entirely reasonable book — one that future ecomusicological scholars absolutely must confront. Furthermore, the critical realist framework of the book is ideal for teaching undergraduates about critical thinking, pluralism, environmental issues, and artistic concerns.

Of the four books under consideration here, Giuseppe Gerbino's Music and the Myth of Arcadia in Renaissance Italy is the most musicological — that is, the most technical, directed as it is at scholars of the culture and music of the Italian Renaissance. In 2010, it won an outstanding book award from the American Musicological Society, and it has been reviewed elsewhere (most accessibly in Bryant 2009). Thus, as this book is not well suited to general ESS audiences, the following will be brief and oriented to the larger 
purposes in this essay: how studying the history of art and culture can illuminate and resonate with ESS.

The pastoral, rooted in classical antiquity, was an idealized mythological place where humans lived harmoniously with each other and nature. Renaissance theater, art, poetry, and music revived interest in it. Gerbino demonstrates the existence and usefulness of the connections between music and the pastoral and how it helps in understanding Renaissance society and its lasting musical traditions. Taking a critical approach to the lack of scholarship on the pastoral in music historiography, Gerbino shows that considering the pastoral impacts changes our understanding of the history of the birth of opera. The usual history of opera holds that the Italians who initially created it circa 1600 were trying to recreate ancient Greek tragedy (this is one aspect of the "re-birth" meaning in the term "re-naissance"). Music was an important aspect of the pastoral dramas that preceded the development of opera; paradoxically, however, while music was important in mythical Arcadia, it was antithetical to the dominant Aristotelian classicism aesthetic of the Renaissance. Thus, music was a contemporary (i.e. Renaissance) addition to drama rather than a reviving of an ancient tradition. Gerbino takes this further to show how the elite classes of fifteenth- and sixteenthcentury Italy used musical pastorals to present themselves as important, sensitive, and superior members of society. Through the rituals enacted in music and the pastoral, a particular group the elite intellectuals and aristocrats) promulgated their social status at the top of the hierarchy and contributed to their lasting artistic contributions (opera).

As with Ingram's discussion of the tensions between popular and art musics, Gerbino elaborates on a similar divide in the Renaissance pastoral between the mundane world of peasants and the poetical abstractions of shepherds. This dichotomy continued with shepherdesses, who were sexually available, and nymphs, who were virtuous unavailable women; thus, elite women could demonstrate their performative talents in an acceptable context. And while the pastoral often provided for Arcadian fantasies to live in a safe and carefree idyll, Gerbino traces the dark side of trouble, death, and unfulfilled love in the musical genre of the madrigal.

Gerbino's book is well documented with primary sources from music, theater, poetry, art, and general 
history, and he has read broadly in the related scholarly fields. My only disappointment is that he does not make ecocritical and ecomusicological connections. I recognize that Gerbino should not be expected to know of every potential realm of scholarship, but he could have found at least two promising possibilities. First, consider his discussions of the distinctions between peasants and shepherds and of the pastoral's dark side; all these could have benefited from something like Leo Marx's simple and complex pastoral. Marx's theory (while not free of critique itself, as Ingram showed) has the advantage of not being historically contingent (as were the diverse philosophies Ingram outlines). Furthermore, ecocriticism has developed a broad program of investigating the literary pastoral in relation to conceptions of the environment (see Hiltner 2011); as with the musicological oversight of the musical pastoral, literary studies had to work to establish the relevance of works about nature (and by women) (Glotfelty 1996). Second, pastoral music, theater, poetry and art were central to the rituals of the social elite in Renaissance Italy; similarly, I ask: Are pastoral myths still central to a modern elite, one that promulgates environmentalism? Is this privileged class still creating cultural mythologies? It is in this sense that we can use history to understand — or at least ask questions about, or reflect on — the present.

But how does Gerbino’s book resonate with ESS curricula? Given the complex scientific and social problems of the environmental crisis, and given the limited time available in educational curricula, why would we want to consider such seemingly tenuous ecomusicological study? In essence, because a liberal education undergirds environmental curricula and because the environmental crisis is a cultural problem that requires broad cultural understanding. ESS curricula are inherently interdisciplinary, and as such they speak directly to the liberal arts and sciences tradition, yet they favor the sciences. What is necessary is improved balance between the arts and sciences; to achieve such balance, ESS curricula should lean a bit more toward the arts and humanities end of the spectrum (while not, of course, overcompensating, for the sciences are still absolutely fundamental). Doing so would demonstrate true interdisciplinarity and encourage students to further link environmental and cultural questions. The medieval liberal arts were comprised of the trivium (grammar, logic, rhetoric) and the quadrivium (arithmetic, geometry, astronomy, music); in that world, the 
sciences and arts come together, and music — which then was conceived more as a speculative rather than practical art — was one of the fundamental disciplines (see Allen forthcoming 2012).

In the end, I do not suggest that we should read Gerbino’s book in an environmental studies curriculum; rather, I do suggest that ecomusicology can open up the possibility of considering such works and their relevance. Further, such opening up need not rely only on musics, histories, and cultures of the West; there are ample opportunities to consider non-Western cultures (see Feld 1990 and Guy 2009). The established fields of ecocriticism and environmental history have equal place with the newly developing ecoarts (theater, visual arts, music) in broadening this curriculum; recent efforts at the 2011 meeting of AESS (and other conferences) indicate increasing dialogue between the sciences, humanities, and arts.

\section{Change in Environmental Studies: A Place for Ecomusicology?}

Ecomusicology is characterized by not being a singular cohesive field, which, as with environmental studies, has both advantages and disadvantages. But beyond such a similarity, I hope to have shown a variety of ways they can speak to each other in productive ways. The four works reviewed here illustrate four of many types of work in ecomusicology: that done by composers and musicians (Adams), ethnographers and anthropologists (Järviluoma et al.), cultural critics (Ingram), and historians of music (Gerbino). Each book serves to illustrate ecomusicology's diversity of both disciplinary approaches and content: from individual experimental work (Adams) to everyday collective soundscapes (Järviluoma), and from modern popular music (Ingram) to historical music of elites (Gerbino). They are by no means unique or all-inclusive; they are but recent book-length examples that provide substantive engagement with the issues that matter to scholars, teachers, and students of ESS.

Interdisciplinarity is one of the key strengths of ESS. However, much of the inter- and cross-disciplinary curricular material has been, and remains, largely within the fields of the natural, physical, and social sciences (Ehrlich 2011). The environmental crisis is at its root a cultural crisis (Allen et al. 2011, White 1967), and understanding the ethical, spiritual, and artistic dimensions of the crisis can inform the important practical 
and applied work in the sciences. The arts and humanities play an important role in understanding the cultural dimension of environmental problems (Allen forthcoming 2012). Productive synergies between fields are part of ESS. Most importantly, however, we need all the resources we can muster. The sciences are primarily a visual culture, but considering human and non-human sound worlds can open our ears, eyes, and minds to find a variety of perspectives on natural and human worlds — not only for their own sake and our enjoyment, but also for how they relate, can be in conflict, and necessitate change.

Musicology itself is an interdisciplinary field, drawing on paleography, literature, mathematics, history, and cultural studies, among others, to say nothing of the performance and practice of various types of musical arts. Ecomusicology builds on this interdisciplinarity. While musicology in and of itself may not be directly relevant to ESS beyond the general liberal arts relationship, ecomusicology can be a productive bridge by opening up possibilities of listening to the world, relating culture with nature, and examining problems from diverse critical positions relevant to ESS.

So, is there a place for ecomusicology in ESS curricula? Only time will tell, but given the wide-ranging interests and long-established work in this field and others closely related to it, I fore-hear such a possibility. 


\section{References}

Allen AS (2012) Ecomusicology: bridging the sciences, arts, and humanities. In: Gallagher DR, Christensen N, Andrews P (eds) Environmental leadership: a handbook. Sage Publications, Thousand Oaks, CA, forthcoming

Allen AS (2013) Ecomusicology. Grove dictionary of American music. Oxford University Press, New York, forthcoming but available at www.ams-esg.org

Allen AS, Grimley DM, Rehding A et al (2011) Colloquy: ecomusicology. J Am Musicol Soc 64:391-424

Bryant B (2009) Review of music and the myth of Arcadia in Renaissance Italy. Curr Musicol 88:93-101

Clark SG, Rutherford MB, Auer MR et al (2011a) College and university environmental programs as a policy problem (Part 1): integrating knowledge, education, and action for a better world? Environ Manag 47:701715

Clark SG, Rutherford MB, Auer MR et al (2011b) College and university environmental programs as a policy problem (part 2): strategies for improvement. Environ Manag 47:716-726

Dunn DD, Crutchfield JP (2009) Entomogenic climate change: insect bioacoustics and future forest ecology. Leonardo 42:239-244

Ehrlich PR (2011) A personal view: environmental education-its content and delivery. J Environ Stud Sci 1:6-13

Feld S (1990) Sound and sentiment: birds, weeping, poetics, and song in Kaluli expression, 2nd edn. University of Pennsylvania Press, Philadelphia

Garrard G (2004) Ecocriticism. Routledge, New York

Glahn DV (2003) The sounds of place: music and the American cultural landscape. Northeastern University Press, Boston

Glotfelty C (1996) Introduction: literary studies in an age of environmental crisis. In: Glotfelty C, Fromm H (eds) The ecocriticism reader: landmarks in literary ecology. University of Georgia Press, Athens, pp xvxxxvii 
Guy N (2009) Flowing down Taiwan's Tamsui river: towards an ecomusicology of the environmental imagination. Ethnomusicology 53:218-248

Hiltner K (2011) What else is pastoral?: renaissance literature and the environment. Cornell University Press, Ithaca

Ingram D (2006) “A balance that you can hear": deep ecology, "serious listening” and the soundscape recordings of David Dunn. Eur J Am Cult 25:123-138

Krause B (1998) Into a wild sanctuary: a life in music \& natural sound. Heyday Books, Berkeley

Krause B (2002) Wild soundscapes: discovering the voice of the natural world. Wilderness Press, Berkeley

Leach EE (2007) Sung birds: music, nature, and poetry in the later middle ages. Cornell University Press, Ithaca

Levin DM (2002) Modernity and the hegemony of vision, 2nd edn. University of California Press, Berkeley

Marler P, Slabbekoorn HW (2004) Nature's music: the science of birdsong. Elsevier Academic, Boston Marx L (1964) The machine in the garden: technology and the pastoral ideal in America. Oxford University Press, New York

Mundy R (2009) Birdsong and the image of evolution. Soc Anim 17:206-223

Orr DW (2010) Hope is an imperative: the essential David Orr. Island Press, Washington, D.C.

Parini J (1995) The greening of the humanities. The New York Times (October 29)

Pedelty M (2008) Woody Guthrie and the Columbia River: propaganda, art, and irony. Pop Music Soc 31:329-355

Pedelty M (2011) Ecomusicology. Momentum (Spring), 22-25

Pijanowski BC, Villanueva-Rivera LJ, Dumyahn SL et al (2011) Soundscape ecology: the science of sound in the landscape. Bioscience 61:203-216

Pinch T, Bijsterveld K (2011) The Oxford handbook of sound studies. Oxford University Press, New York Ross A (2008) Letter from Alaska: song of the earth. The New Yorker (May 12), 76-81

Schafer RM (1994) The soundscape: our sonic environment and the tuning of the world. Destiny Books, 


\section{Rochester, VT}

Schafer RM, Davis B, Truax B (1977) Five village soundscapes. A.R.C. Publications, Vancouver Smith M (2004) Hearing history: a reader. University of Georgia Press, Athens

Smith M (2007) Sensing the past: seeing, hearing, smelling, tasting, and touching in history. University of California Press, Berkeley

Snow CP (1959) The two cultures and the scientific revolution. Cambridge University Press, New York Toliver B (2004) Eco-ing in the Canyon: Ferde Grofé's Grand Canyon suite and the transformation of wilderness. J Am Musicol Soc 57:325-367

Turner K, Freedman B (2004) Music and environmental studies. J Environ Educ 36:45-52

White L (1967) The historical roots of our ecologic crisis. Science 155 (3767):1203-1207

Wilson EO (1998) Consilience: the unity of knowledge. Knopf, New York 